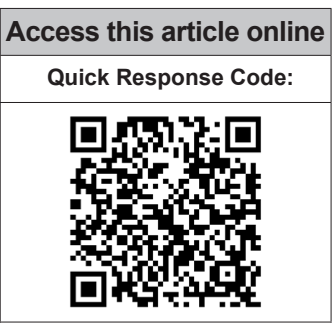

Website:

www.jponline.org

DOI:

10.4103/JLP.JLP_129_17
Departments of Pathology and ${ }^{2}$ Gastroenterology,

Dayanand Medical College and Hospital, Ludhiana,

Punjab, 'Department of Cardiology, Institute of Medical Sciences, Banaras Hindu University, Varanasi, Uttar Pradesh, India

Address for correspondence:

Dr. Ruchita Tyagi, Department of Pathology, Dayanand Medical College and Hospital, Tagore Nagar, Ludhiana, Punjab, India.

E-mail: ruchitatyagi@ gmail.com

Submission: 10-08-2017 Accepted: 27-11-2017

Entamoeba histolytica:

\title{
A surprising coexistence with adenocarcinoma - Never brush aside brushings for biopsy
}

\author{
Palvi Goel, Ruchita Tyagi, Gursheen Kaur ${ }^{1}$, Bhavna Garg, Pavneet Kaur Selhi, \\ Harpreet Kaur, Varun Mehta², Neena Sood
}

\begin{abstract}
:
Entamoeba histolytica has been rarely reported as superadded infection over carcinomatous growth on rectal brushings. We present a case of 68-year-old male who presented with abdominal pain and bleeding per rectum who was found to have an ulceroproliferative growth on sigmoidoscopy. Rectal brushings revealed coexistence of $E$. histolytica with malignant cells of adenocarcinoma. No organism was detected on biopsy of the tumor, which also showed adenocarcinoma, because of possible surface colonization of the tumor by Entamoeba. This case highlights the role of rectal brushings in detecting superadded infection in a case where both brushings and biopsy were performed. It is always important to report infection superadded on malignancies for optimum management of the patients.
\end{abstract}

Key words:

Adenocarcinoma, brushings, Entamoeba, rectal, superadded

\section{Introduction}

Tntestinal amoebiasis caused by Entamoeba Listolytica occurs throughout the world and about 40 million develop colitis or extraintestinal abscesses out of which 40,000 die annually. ${ }^{[1]}$ The maximum incidence of E. histolytica infection is seen in Central and South America, Africa, and the Indian subcontinent. ${ }^{[2]}$

Colonic amoebiasis is the most common presentation of intestinal amoebiasis while extraintestinal amoebiasis most commonly presents as amoebic liver abscess. ${ }^{[3]}$ Microscopic examination is a cost-effective and confirmatory diagnostic modality in endemic areas. ${ }^{[4,5]}$

There are several case reports describing the cytology of E. histolytica in hepatic abscesses.

This is an open access article distributed under the terms of the Creative Commons Attribution-NonCommercial-ShareAlike 3.0 License, which allows others to remix, tweak, and build upon the work non-commercially, as long as the author is credited and the new creations are licensed under the identical terms.

For reprints contact: reprints@medknow.com
However, coexistence of this organism, with rectal carcinoma, and detected on rectal brushings, has been rarely reported. To the best of our knowledge, this is the first case report describing cytology of $E$. histolytica present concomitantly with a rectal malignancy.

\section{Case Report}

A 68-year-old man presented with complaints of pain abdomen for 15 days and recurrent episodes of hematochezia for 5 days. A nondiabetic with no other significant medical history, he underwent sigmoidoscopy with rectal brushings and biopsy which were sent for cytological and histopathological evaluation, respectively. Stool examination was not performed. Sigmoidoscopy revealed a broad based, lobulated proliferative growth measuring

How to cite this article: Goel P, Tyagi R, Kaur $G$, Garg B, Selhi PK, Kaur H, et al. Entamoeba histolytica: A surprising coexistence with adenocarcinoma - Never brush aside brushings for biopsy. J Lab Physicians 2018;10:251-4. 


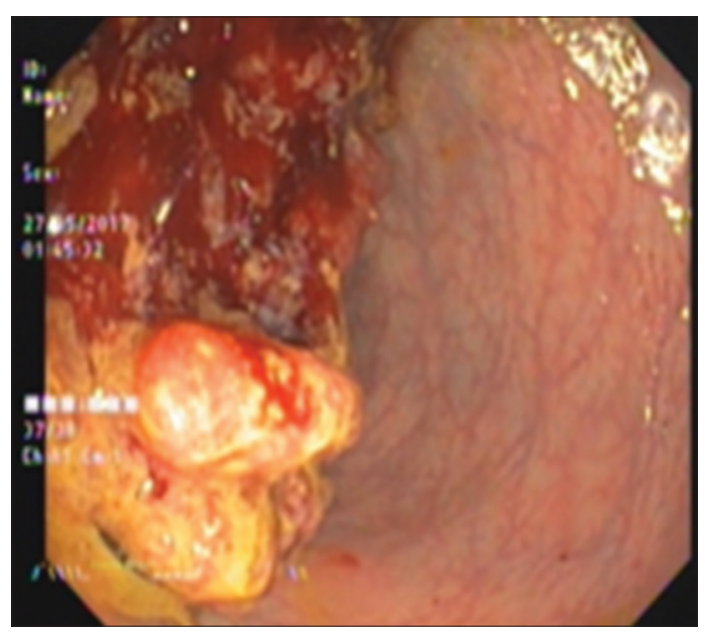

Figure 1: Sigmoidoscopy showing lobulated proliferative growth occluding recto sigmoid lumen

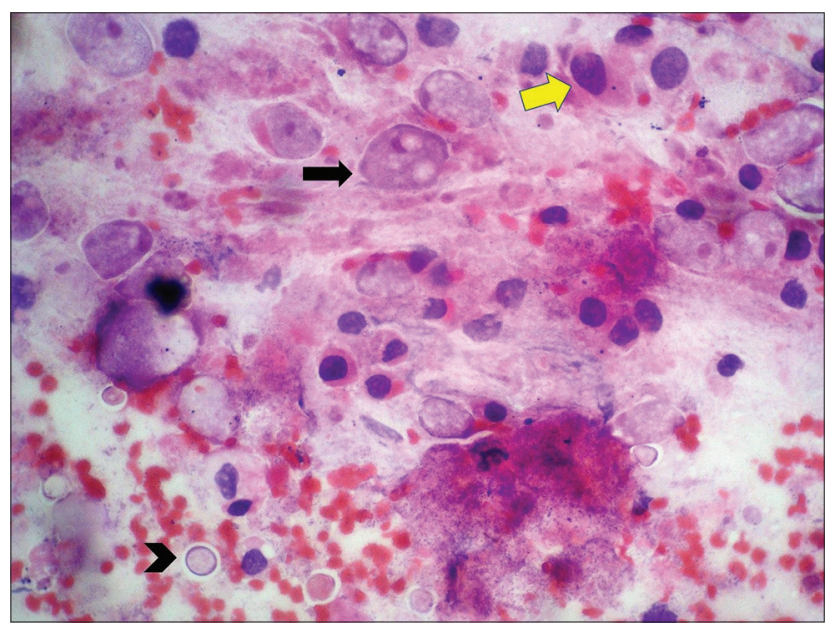

Figure 3: Rectal brushings showing trophozoites displaying erythrophagocytosis (arrow) and cysts (arrowhead) along with malignant cells (yellow arrow) on ( $\mathrm{H}$ and $\mathrm{E}, \times 400)$ smear

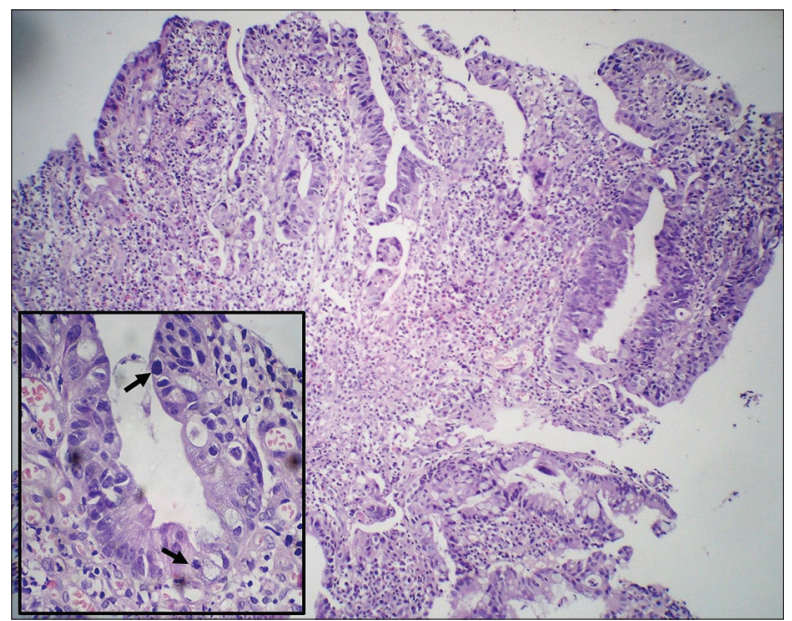

Figure 5: Rectal biopsy showing adenocarcinoma displaying nuclear stratification and crowding ( $\mathrm{H}$ and $\mathrm{E}, \times 40)$ with frequent atypical mitotic figures in inset (arrow) $(\times 400)$

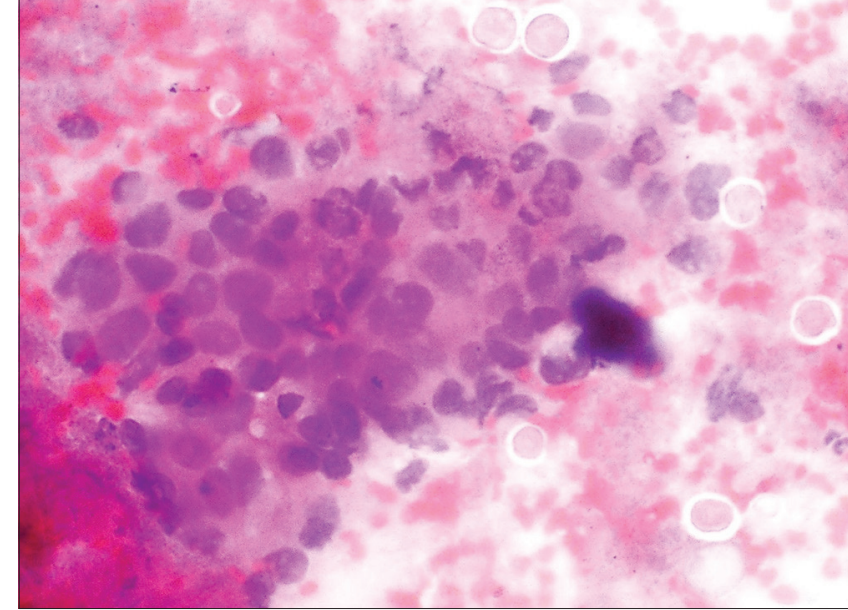

Figure 2: Rectal brushings showing Entamoeba cysts and clusters of malignant cells on $(\mathrm{H}$ and $\mathrm{E}, \times 400)$ smear

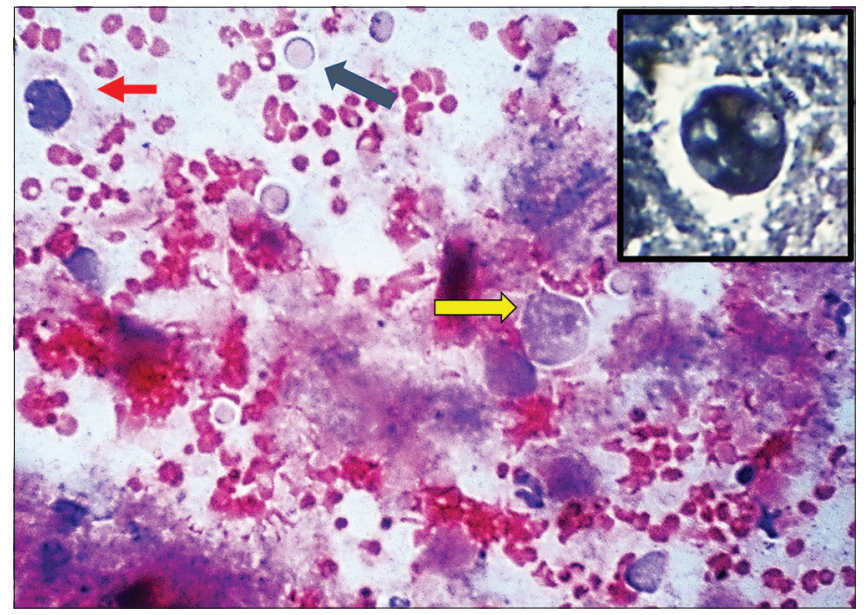

Figure 4: Periodic acid-Schiff stain highlighting trophozoites (yellow arrow), cysts (black arrow) and malignant cell (red arrow). Inset showing trophozoite on (PTAH, $\times 400)$

$5 \mathrm{~cm} \times 4.1 \mathrm{~cm}$ in size, in the rectosigmoid region, located at $14 \mathrm{~cm}$ from anal verge and was partially obliterating the rectosigmoid lumen [Figure 1].

Cytological examination of the rectal brushings showed few cohesive clusters, some with attempted gland formation, composed of cells exhibiting moderate nuclear pleomorphism, nucleomegaly, irregular nuclear contours, clumped chromatin, and scanty cytoplasm [Figure 2]. Also seen were numerous cysts of E. histolytica surrounded by a halo along with trophozoites containing granular cytoplasm and exhibiting hemophagocytosis [Figure 3]. periodic acid-Schiff (PAS) and phosphotungstic acid hematoxylin (PTAH) stains were also done to highlight the trophozoites [Figure 4]. Thus, cytological diagnosis of E. histolytica infection with adenocarcinoma rectum was made. 
Histopathological examination confirmed the diagnosis of adenocarcinoma seen as glands displaying crowding and back-to-back arrangement and nuclear stratification with villi formation. The individual cells displayed marked nuclear pleomorphism, hyperchromasia with many atypical mitotic figures [Figure 5]. Focus of invasion was noted in the underlying tissue which also showed dense inflammatory infiltrate composed of neutrophils, eosinophils, and lymphocytes. However, no cysts or trophozoites of E. histolytica were evident on biopsy sections.

Informed consent was obtained from the patient for utilizing his data for academic purpose. Thereafter, the patient refused further treatment and was lost to clinical follow-up.

\section{Discussion}

E. histolytica, an amoebic protozoan parasite, occurs in the cyst form and trophozoite form. The infection occurs through feco-oral route after consumption of water or food contaminated with cyst form. ${ }^{[2]}$

Amoebiasis is defined as infection with E. histolytica, regardless of symptomatology. ${ }^{[6]}$ Although both genders and all ages are affected; males are more commonly affected than females. ${ }^{[4]}$

Patients may be asymptomatic or present with abdominal pain, copious diarrhea admixed with blood and mucus. ${ }^{[7,8]}$ This patient only had abdominal pain. On sigmoidoscopy, flask shaped ulcers covered with slough are usually present. ${ }^{[8]}$ However, in our case, a broad based, lobulated, soft-tissue density mass lesion was there in the rectosigmoid region measuring $5 \mathrm{~cm} \times 4.1 \mathrm{~cm}$ which was partially obliterating the rectosigmoid lumen and through which scope was not negotiable. Microscopic examination is mandatory to determine nature of this growth and differentiate between amoeboma and carcinoma. ${ }^{[9]}$ Since there was no history of diarrhea/clinical symptoms suggestive of amoebiasis in this case, detecting E. histolytica on rectal brushings was an unexpected finding which made this case unique.

Identification of the parasite is possible because of characteristic morphology of trophozoites which exhibit erythrophagocytosis along with prominent karyosome. Foamy macrophages are a cause of confusion but they will not display hemophagocytosis. ${ }^{[8,10]}$ PAS and PTAH stains highlight the trophozoites and distinguish them from foamy macrophages. The cyst forms are surrounded by refractile membrane with no chromatid body/glycogen mass seen. ${ }^{[8]}$
Other modalities for diagnosis of E. histolytica include examination of stools for trophozoites and cysts, serological tests, polymerase chain reaction, and enzyme-linked immunosorbent assay-based tests. ${ }^{[8,11]}$ However, these were not performed in our case as there was no clinical suspicion of amoebiasis and the patient was lost to follow-up. E. histolytica was possibly present only as surface colonization of the carcinomatous growth, which explains the absence of E. histolytica in biopsy sections. Hence, rectal brushings proved to be instrumental in making the complete diagnosis of adenocarcinoma with superadded E. histolytica infection. Brush cytology has comparable diagnostic sensitivity for gastrointestinal lesions because brushings can cover larger mucosal surface and collect diagnostic material even from stenosed areas where sigmoidoscope may not be negotiable, like in this case. ${ }^{[12]}$ Combining brush cytology with histopathology is a routine practice in our tertiary care institute to improve the diagnostic sensitivity.

Till date very few case reports have described coexistence of E. histolytica with malignancy, especially on cytology. ${ }^{[9]}$ Other organism that has also been reported to be associated with gastrointestinal malignancies as superadded infection include Candida. ${ }^{[13]}$

Thus, the clinician as well as the pathologists needs to be vigilant about coexistence of malignancy with superadded infections like E. histolytica in patients belonging to endemic areas and presenting with abdominal complaints. This case highlights the role of cytology in diagnosing such superadded infections, which may be missed on biopsy alone. Hence, it is always pertinent to take brushings along with biopsy while investigating any colonic masses to obtain a comprehensive diagnosis.

\section{Informed Consent}

Written informed consent was obtained from the patient.

\section{Declaration of patient consent}

The authors certify that they have obtained all appropriate patient consent forms. In the form, the patient has given him consent for him images and other clinical information to be reported in the journal. The patient understands that name and initials will not be published and due efforts will be made to conceal identity, but anonymity cannot be guaranteed.

\section{Financial support and sponsorship Nil.}

\section{Conflicts of interest}

There are no conflicts of interest. 


\section{References}

1. Li E, Stanley SL Jr. Protozoa. Amebiasis. Gastroenterol Clin North Am 1996;25:471-92.

2. Singh U, Petri WA Jr. Amoebas. In: Gillespie SH, Pearson RD, editors. Principles and Practice of Clinical Parasitology. Chichester: John Wiley \& Sons, Ltd.; 2001. p. 197-218.

3. $\mathrm{WHO} / \mathrm{PAHO} / \mathrm{UNESCO}$ Report. A consultation with experts on amoebiasis. Mexico City, Mexico 28-29 January, 1997. Epidemiol Bull 1997;18:13-4.

4. Gupta KB, Manchanda M, Chaudhary U, Verma M. Superior vena cava syndrome caused by pulmonary amoebic abscess. Indian J Chest Dis Allied Sci 2006;48:275-7.

5. Sultan A, Raza A, Khan HM, Khalid S, Akhtar A, Shameem M. Entamoeba histolytica pleuropulmonary infection case report. Int J Adv Case Rep 2015;2:171-3.

6. Ximénez C, Morán P, Rojas L, Valadez A, Gómez A. Reassessment of the epidemiology of amebiasis: State of the art. Infect Genet Evol 2009;9:1023-32.

7. Ng DC, Kwok SY, Cheng Y, Chung CC, Li MK. Colonic amoebic abscess mimicking carcinoma of the colon. Hong Kong Med J 2006;12:71-3.
8. Chatterjee KD, editor. Subphylum sarcomastigophora Superclass sarcodina, class rhizopodea: Order amoebida. In: Parasitology (Protozoology and Helminthology) in Relation to Clinical Medicine. $12^{\text {th }}$ ed. Kolkata, India: Sree Saraswaty Press Ltd.; 2001. p. 14-36.

9. Misra SP, Misra V, Dwivedi M. Ileocecal masses in patients with amebic liver abscess: Etiology and management. World J Gastroenterol 2006;12:1933-6.

10. Zhu H, Min X, Li S, Feng M, Zhang G, Yi X, et al. Amebic lung abscess with coexisting lung adenocarcinoma: A unusual case of amebiasis. Int J Clin Exp Pathol 2014;7:8251-4.

11. Skappak C, Akierman S, Belga S, Novak K, Chadee K, Urbanski SJ, et al. Invasive amoebiasis: A review of Entamoeba infections highlighted with case reports. Can J Gastroenterol Hepatol 2014;28:355-9.

12. Bardawil RG, D'Ambrosio FG, Hajdu SI. Colonic cytology. A retrospective study with histopathologic correlation. Acta Cytol 1990;34:620-6.

13. Delsing CE, Bleeker-Rovers CP, van de Veerdonk FL, Tol J, van der Meer JW, Kullberg BJ, et al. Association of esophageal candidiasis and squamous cell carcinoma. Med Mycol Case Rep 2012;1:5-8. 